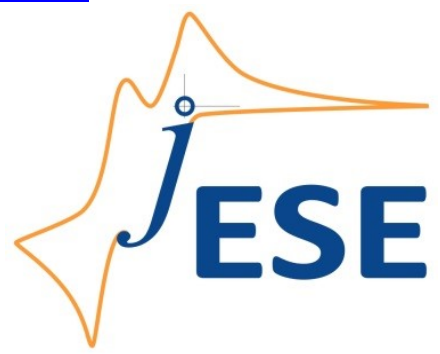

Open Access : : ISSN 1847-9286

www.jESE-online.org

Original scientific paper

\title{
Electrochemical evaluation of corrosion resistance of chromium plated nickel and copper tin alloys. A comparative study
}

\author{
Chike F. Oduoza ${ }^{凶}$, Stacey Hingley \\ Faculty of Science and Engineering, University of Wolverhampton, WV11LY, UK \\ Corresponding author - E-mail: ${ }^{\circledR}$ C.F.Oduoza@wlv.ac.uk; Tel.: +44-(0) 1902 323944; \\ Fax: +44-(0) 190232754
}

Received: August 30, 2017; Revised: December 1, 2017; Accepted: December 19, 2017

\begin{abstract}
Engineering materials and composites are frequently exposed to aggressive and chemically toxic environments with high probability for rapid corrosion and consequent deterioration and catastrophic degradation. Occasionally, a new legislation regulates against the use of existing materials, necessitating the development of new methodologies or new materials in order to reduce material corrosion rates. The aim of this study is to test the corrosion resistance of the copper tin alloy, a material that could replace nickel compounds, recently reclassified as suspected carcinogens. Standard sizes of precut nickel and brass panels were produced and then plated with different thicknesses of copper tin alloy and chromium for additional protection. Evaluation of plated materials for corrosion rate and resistance was carried out using linear polarisation, electrochemical impedance and accelerated destructive testing. Corrosion testing of the materials assessed qualitatively and quantitatively, showed that corrosion resistance was dependent on a combination of factors, including the thickness of chromium plating, type of material, type of testing and duration in a corrosion chamber. While linear polarisation experiment was useful in establishing corrosion rate of sample, electrochemical impedance and accelerated destructive testing experiments assessed corrosion resistance of the materials.
\end{abstract}

\section{Keywords}

Nickel, Copper-tin alloy deposit; Chromium deposit; Corrosion resistance; Corrosion testing

\section{Introduction}

Electrodeposited nickel is widely used in many applications. A typical application of plated nickel is in corrosion protection, particularly in conjunction with chromium plating. The reclassification of nickel and its salts to a more toxic chemical status has led the electroplating industry to research in order to find a replacement for the nickel layer [1]. In this study, corrosion rate and resistance of 
the chromium plated copper tin alloy has been evaluated as an alternative to the chromium plated nickel. The colour and surface imaging of copper tin alloy with chromium deposits compared to the nickel deposit have already been studied by Hingley and Oduoza [1].

The EU risk assessment committee was set up in 1966 to investigate nickel and its compounds with regard to its effect on human health and environmental impact. Danish Environmental Protection Agency (D-EPA) as a Rapporteur was delegated to evaluate nickel and soluble nickel compounds (nickel sulphate, nickel chloride, nickel carbonate, nickel nitrate). In February 2007, there was a reclassification of the five nickel substances as category 1-human carcinogens by inhalation (carcinogenic to man) and category 2 - reproductive toxicants (may cause harm to the unborn child) and chronic toxicant. Nickel metal has been classified as category 3-carcinogen (limited evidence of a carcinogenic effect) and chronic toxicity [1].

The aim of this study is to test the corrosion resistance of the copper tin alloy that could replace nickel compounds reclassified as suspected carcinogens.

Corrosion resistance of a deposit is important to manufacturers and consumers since it determines the level of corrosion protection and life of the product. Since an evaluation of a material corroding in real time can be very time consuming, electrochemical techniques can be used to accelerate the corrosion process and collate data rapidly. The principle behind this mode of testing is to apply the potential (voltage) across an electrochemical cell to cause current to flow in order to mimic the rate of electrochemical reaction taking place at electrodes. The electrode reaction is transfer of electrons from the electrode material to form ions (the corrosion process), triggered by the applied potential resulting in the flow of an electric current $[2,3]$.

Other corrosion tests used within the electroplating industry for measuring corrosion rates include Neutral Salt Spray (NSS) and Copper Accelerated Acetic Acid Salt Spray (CASS) methods [4]. Specifications used throughout this study make an important part of the electroplating industry and allow an accurate comparison of deposits used [4-6]. CASS is a methodology used to enhance corrosion rate/resistance of a material in order to monitor the resilience of the material to corrosion.

\section{Experimental}

\section{Procedure for preparation of sample for electrodeposition}

Brass panels (size $10 \times 7.5 \times 0.05 \mathrm{~cm}$ ) of 70:30 copper to zinc ratio were used as the substrate for all experiments carried out in this study. Figure 1 shows the sequence for electrodeposition of nickel and chromium on brass panels. Nickel was plated to a thickness of $20 \mu \mathrm{m}$ followed by $0.3 \mu \mathrm{m}$ of chromium, if required. The formulations and electroplating conditions for nickel and chromium depositions have been reported previously [7].

The electroplating sequence for deposition of white Cu-Sn alloy is outlined in Figure 2. After pretreatment, copper was electrodeposited to a thickness of $20 \mu \mathrm{m}$, followed by deposition of white Cu-Sn alloy at thicknesses of either $0.5 \mu \mathrm{m}$ or $2 \mu \mathrm{m}$ and then chromium to a thickness of $0.3 \mu \mathrm{m}$, if applicable. All operating conditions for deposition of copper and white Cu-Sn alloy were described previously [7]. White Cu-Sn alloy deposit is not normally plated above a specific thickness due to a possible change in appearance from a silvery bright to dull grey colour.

The sequence for electrodeposition of yellow Cu-Sn alloy is identical to those of white Cu-Sn alloy, followed by deposition of varying thicknesses of yellow Cu-Sn alloy, topped up with $0.5 \mu \mathrm{m}$ of white Cu-Sn alloy, if applicable and finally $0.3 \mu \mathrm{m}$ of chromium deposited, if specified. The formulation and operating parameters for the yellow Cu-Sn alloy were described by Hingley [7]. 


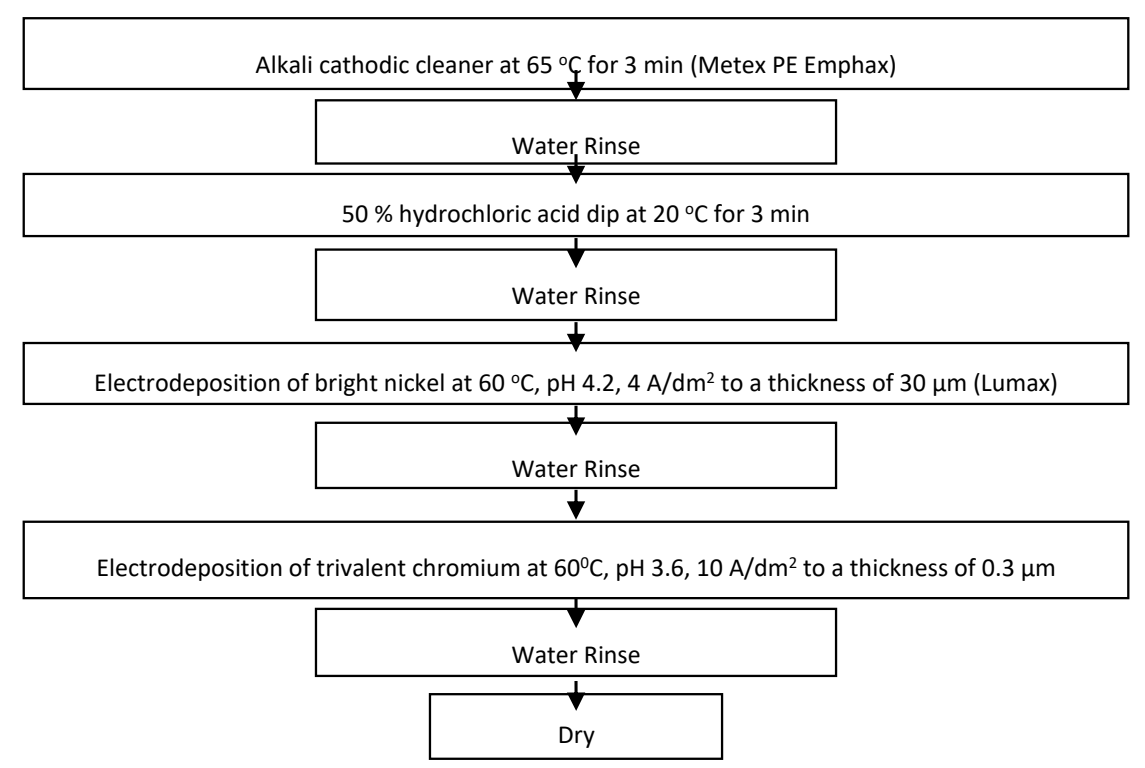

Figure 1. Flow chart for electrodeposition of nickel and trivalent chromium on brass substrate

Details of the appearance, testing and deposits structure analysis for the panels have been reported elsewhere [1]. The corrosion resistance of each deposit was assessed electrochemically by linear polarisation [3,8-13], electrochemical impedance spectroscopy experiments and also by accelerated salt spray testing using copper accelerated acetic acid salt spray. All electroplated panels were analysed thrice on the same panel for corrosion resistance, appearance and deposit structure. The Nyquist and Bode plots for the electrochemical impedance study were taken from one set of results to characterise the selected deposits.

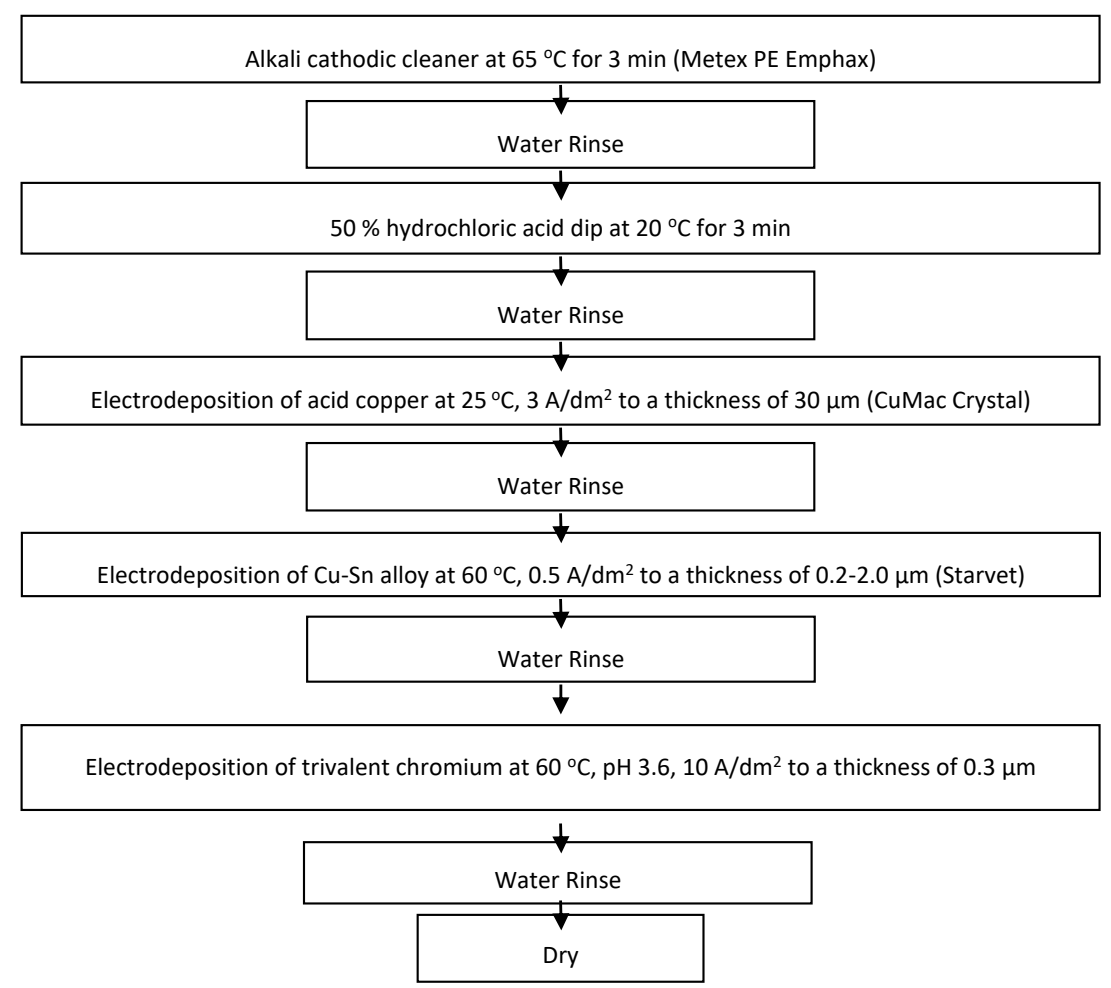

Figure 2. Flow chart for electrodeposition of white Cu-Sn and trivalent chromium on brass substrate.

Testing of plated panels for corrosion rate and resistance

Evaluation of the deposits was also carried out by visual examination and guided by the specification ASTM B 537-70 [14]. It is determined by the percentage of corrosion that covers both 
the deposit and substrate. The corrosion rating is given in two values $X / Y$, with ' $X$ ' referring to the coverage and appearance of the substrate corrosion (known as the protection rating) and ' $Y$ ' referring to the coverage and appearance of the coating itself and is known as the appearance rating. All ratings are given as a value of $1-10$ with 10 being the best (no corrosion) and 1 being the worst (corrosion seen all over the specimen).

\section{Instrumentation for linear polarisation and electrochemical impedance spectroscopy}

Potentiostat, EG+G Instruments, Model 263A, was used to determine the corrosion current density ( $\left.i_{\text {corr }}\right)$. These experiments were carried out in $5 \%$ neutral sodium chloride solution using an $\mathrm{Ag} / \mathrm{AgCl}$ reference electrode over a potential range of $+/-20 \mathrm{mV}$ versus open circuit potential. The equilibrium time for which $1 \mathrm{~cm}^{2}$ surface of panel was in contact with the $\mathrm{NaCl}$ varied from 30 to 60 minutes. Figure 3 shows the corrosion cell used for the linear polarisation and electrochemical impedance spectroscopy testing [6]. The working electrode is the electroplated brass panel of $1 \mathrm{~cm}^{2}$ area immersed in $5 \%$ neutral $\mathrm{NaCl}$ solution, the auxiliary electrode is platinum mesh, while the reference electrode is $\mathrm{Ag} / \mathrm{AgCl}$.

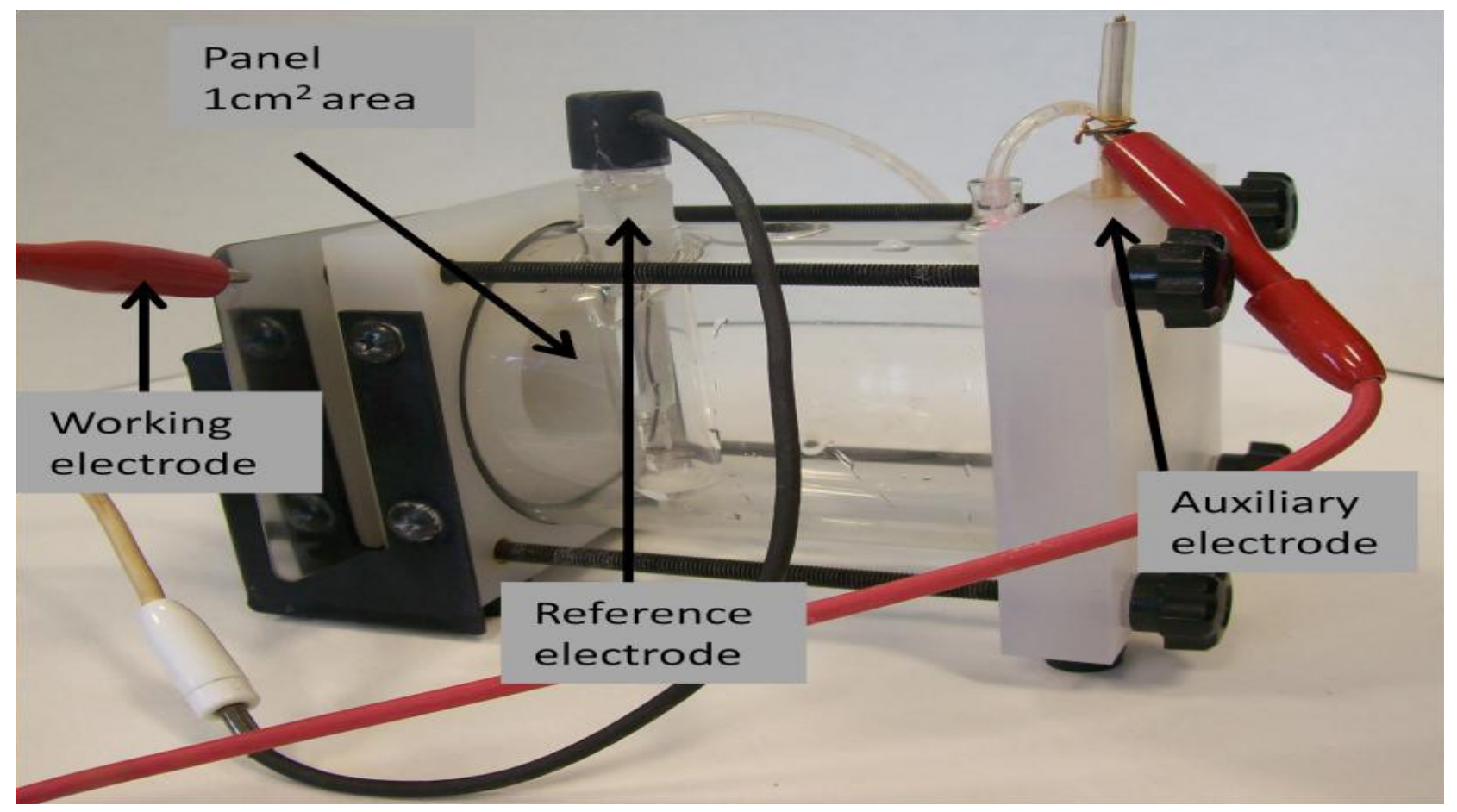

Figure 3. Corrosion cell used for linear polarisation and electrochemical impedance spectroscopy experiments

\section{Electrochemical impedance spectroscopy}

This study was carried out with a Solartron 1252A Frequency Response Analyser (FRA) with Princeton Applied Research Potentiostat/Galvanostat, Model 263A, and ZPlot software. Experiments were carried out using the test panel in $5 \%$ neutral $\mathrm{NaCl}$ solution, with equilibrium time prior measurements varied from 30 to 60 minutes. All electrochemical impedance experiments were carried out at the open circuit potential (OCP), with signal amplitude of $15 \mathrm{mV}$, within a frequency range of $10^{6}$ to $10^{-1} \mathrm{~Hz}$, and 10 points measured frequency decade.

Figure 4 shows a simple electrical equivalent circuit with one-time constant that has usually been used for measured impedance data fittings and determination of all components, i.e. corrosion resistance $\left(R_{\text {corr }}\right)$, solution resistance $\left(R_{\mathrm{s}}\right)$ and double-layer capacitance (CEDL) of a corrosive electrode. 


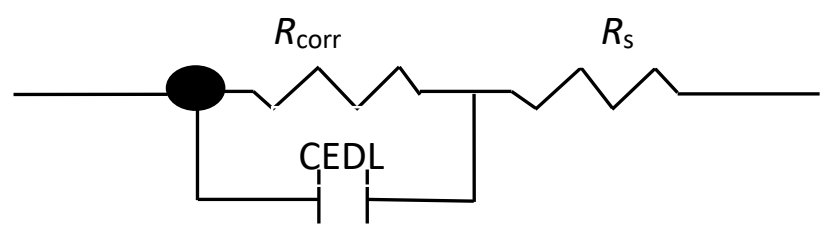

Figure 4. One time constant-electrical equivalent circuit showing electrical behaviour of the cell with corrosive electrode [2]

\section{Copper accelerated acetic acid salt spray test}

CASS testing was carried out in salt solution comprising sodium chloride $45-55 \mathrm{~g} / \mathrm{l}$, copper chloride $0.25 \mathrm{~g} / \mathrm{l}$ and made up to 1 litre. The $\mathrm{pH}$ was adjusted with glacial acetic acid. Air pressure was 0.08 $0.12 \mathrm{MPa}$ and humidifier temperature was $60-65^{\circ} \mathrm{C}$. The chamber temperature was maintained within the range of $48-51^{\circ} \mathrm{C}$. The sample collection rate was 1.0-2.0 ml/hour [15]. Experiments were carried out in a fog chamber with a provision for heating, salt reservoir, supply of compressed air, at least one atomising nozzle, specimen support, and means of control. All equipment was corrosion resistant to the fog $[6,14]$.

The test specimen was thoroughly cleaned to avoid any side influence on the corrosion resistance of the deposit. To clean the sample, 10 grams of magnesium oxide powder in $100 \mathrm{ml}$ of distilled water was used to wipe over the sample's surface with cotton wool and rinsed with warm water before drying. In order to avoid localised corrosion on the non-protected areas, any cut edge or jig point was masked with either pressure sensitive tape, or stopping off by lacquer or wax [14]. Positioning of test specimen to expose the test area was carried out at a $15^{\circ}$ parallel to the principal direction of horizontal flow of fog through the chamber, based on the dominant surface under test. Test specimens were not allowed to touch each other or with any other metal to avoid contamination [14]. Each chamber, containing at least two fog collectors was used to evaluate the collection rate and also to analyse the salt concentration and $\mathrm{pH}$ [14].

The standard test method used for CASS testing was ASTM B 368-97 [15] using Liebisch, model 33649 corrosion cabinet. This method was used to evaluate performance of the decorative process for copper/nickel/chromium, or nickel/chromium plating on substrates. CASS was used throughout for corrosion testing and appears to be the preferred method in the electroplating industry compared to NSS which is relatively slow to corrode the nickel/chromium deposits.

Atomic force microscopy (AFM) surface imaging technique was used to evaluate the surface properties of the plated samples at the nanometer scale. The technique produced a three-dimensional image that was used to characterise roughness, depth, and particle size of the surface [1].

\section{Results and discussion}

\section{Electrochemical corrosion rate and resistance results}

Linear polarisation data was used to calculate corrosion current values, which were used to estimate corrosion rate of each electroplated deposit. Polarization resistance $\left(R_{\mathrm{P}}\right)$ is defined as the slope of the potential $(E)$ vs. current density $(j)$ plot measured close to the corrosion potential according to equation (1):

$$
R_{\mathrm{p}}=\frac{\Delta E}{\Delta j}
$$

In equation (1), $R_{\mathrm{P}}$ is polarisation (corrosion) resistance in $\Omega \mathrm{cm}^{2}, \Delta E$ is change in potential in $V$ and $\Delta j$ is change in current density in $\mathrm{A} / \mathrm{cm}^{2}$. 
There are lot of papers in the literature reporting application of the linear polarisation technique, including that of Kouril et al. [16] who calculated the polarisation (corrosion) resistance of corroding reinforcements used in concrete. For a practical determination on how fast the deposit corrodes and to estimate how long the service life will be, equation (2), demonstrating the mathematical relationship between $j_{\text {corr }}$ and $R_{\mathrm{p}}$, is used [2]:

$$
j_{\text {corr }}=\frac{1}{2.303 R_{\mathrm{p}}} \frac{B_{\mathrm{a}} B_{\mathrm{c}}}{\beta_{\mathrm{a}}+\beta_{\mathrm{c}}}
$$

In equation (2) $j_{\text {corr }}$ is corrosion current density in $\mathrm{A} / \mathrm{cm}^{2}, R_{\mathrm{p}}$ is corrosion resistance in $\Omega \mathrm{cm}^{2}, \beta_{\mathrm{a}}$ is anodic Tafel slope, while $\beta_{\mathrm{c}}$ is cathodic Tafel slope, referred to as the Tafel constant. Calculation of the corrosion rate was carried out according to Weast [17] using equation (3) showing how the corrosion current can be converted to a corrosion rate in millimetres per year (MPY) [2]:

Corrosion rate, $\mathrm{mm}$ year ${ }^{-1}=j_{\text {corr }} \Lambda(1 / \rho) \varepsilon$

In equation (3), $j_{\text {corr }}$ is corrosion current density in $\mathrm{A} / \mathrm{cm}^{2}, \Lambda$ is a combination of several conversion terms equal to $1.2866 \times 10^{5}$ [equivalents $\times \mathrm{mm}$ ]/[C $\times \mathrm{cm} \times$ year], $\rho$ is metal density $\left(\mathrm{g} / \mathrm{cm}^{3}\right)$, while $\varepsilon$ is equivalent weight of the metal (molecular weight of the metal divided by the number of electrons in the anodic half reaction) in g/equivalent.

Table 1 shows the results of the linear polarisation experiments highlighting data for polarisation resistance, corrosion current and an estimate of corrosion rate for the electroplated panels. The polarisation resistance measures resistance to corrosion in $\mathrm{k} \Omega \mathrm{cm}^{2}$ while average corrosion current quantifies the current associated with corrosion of the deposit expressed in $\mathrm{nA} / \mathrm{cm}^{2}$. Corrosion rate describes the rate of corrosion measured in mm/year. For nickel deposit, corrosion rate is $0.20 \mathrm{~mm}$ per year, but with chromium as topcoat, the corrosion rate decreased to $0.03 \mathrm{~mm}$ per year. This shows clearly that chromium deposit can significantly reduce the corrosion rate, providing an additional protection to nickel deposit.

Data in Table 1 calculated on the basis of linear polarisation graphs presented in Figure 5 show that polarization (corrosion) resistance increases with coating thickness for white Cu-Sn alloy, however, when top is plated with chromium the resistance to corrosion levels off (compare $0.5 \mu \mathrm{m}$ white $\mathrm{Cu}$-Sn alloy with $2.0 \mu \mathrm{m}$ white $\mathrm{Cu}$-Sn alloy both plated with chromium).

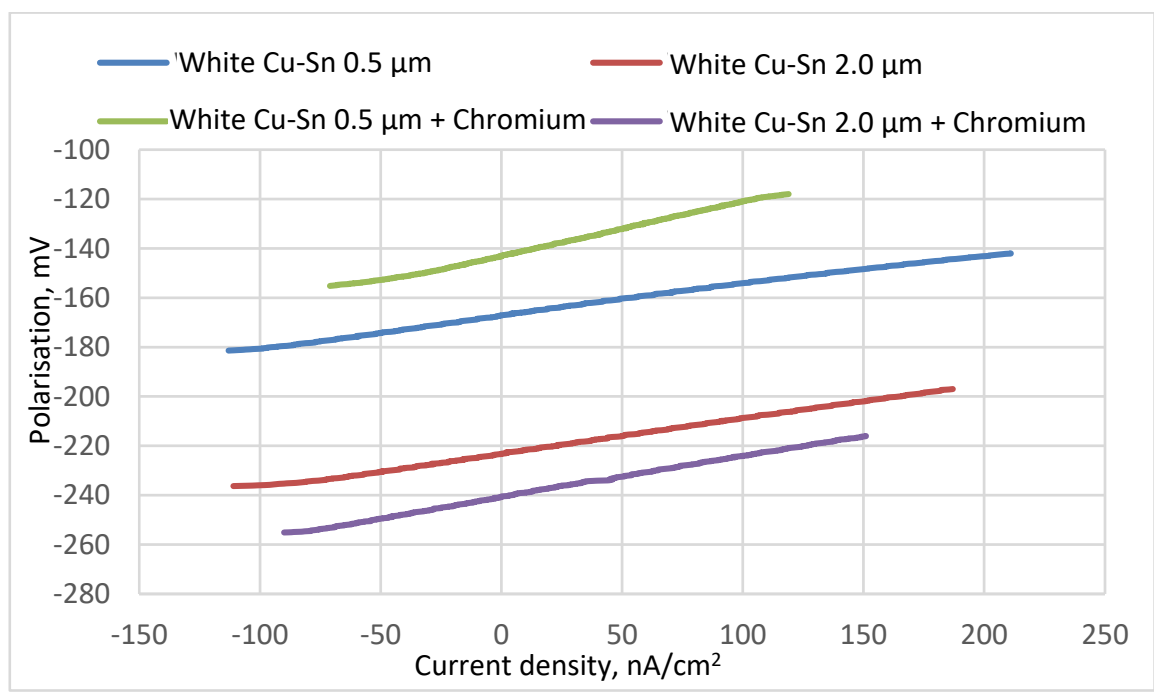

Figure 5. Linear polarisation graphs for the white CU-Sn alloy deposit with and without chromium as a topcoat 
Table 1. Linear polarisation data (polarisation resistance, corrosion current density and calculated corrosion rate) for electroplated deposits.

\begin{tabular}{|c|c|c|c|}
\hline Panel Identification & $R_{\mathrm{p}} / \mathrm{k} \Omega \mathrm{cm}^{2}$ & Average $j_{\text {corr }} / \mathrm{nA} \mathrm{cm}^{-2}$ & Corrosion rate, $\mathrm{mm}$ per year \\
\hline Nickel $20 \mu \mathrm{m}$ & 47 & 482 & 0.20 \\
\hline Nickel $20 \mu \mathrm{m}+$ Chromium & 328 & 77 & 0.03 \\
\hline White Cu-Sn alloy $0.5 \mu \mathrm{m}$ & 156 & 197 & 0.096 \\
\hline White $\mathrm{Cu}-\mathrm{Sn}$ alloy $2.0 \mu \mathrm{m}$ & 337 & 98 & 0.05 \\
\hline White Cu-Sn alloy $0.5 \mu \mathrm{m}+$ chromium & 207 & 108 & 0.05 \\
\hline White Cu-Sn alloy $2.0 \mu \mathrm{m}+$ chromium & 171 & 132 & 0.06 \\
\hline $\begin{array}{l}\text { Yellow Cu-Sn alloy } 4.0 \mu \mathrm{m}+ \\
\text { White Cu-Sn alloy } 0.5 \mu \mathrm{m}\end{array}$ & 17 & 1848 & 0.91 \\
\hline $\begin{array}{l}\text { Yellow Cu-Sn alloy } 12.0 \mu \mathrm{m}+ \\
\text { White Cu-Sn alloy } 0.5 \mu \mathrm{m}\end{array}$ & 63 & 672 & 0.33 \\
\hline $\begin{array}{l}\text { Yellow Cu-Sn alloy } 24.0 \mu \mathrm{m}+ \\
\text { White Cu-Sn alloy } 0.5 \mu \mathrm{m}\end{array}$ & 104 & 273 & 0.13 \\
\hline $\begin{array}{l}\text { Yellow Cu-Sn alloy } 4.0 \mu \mathrm{m}+ \\
\text { White Cu-Sn alloy } 0.5 \mu \mathrm{m}+\text { chromium }\end{array}$ & 22 & 1232 & 0.61 \\
\hline $\begin{array}{l}\text { Yellow Cu-Sn alloy } 12.0 \mu \mathrm{m}+ \\
\text { White Cu-Sn alloy } 0.5 \mu \mathrm{m}+\text { chromium }\end{array}$ & 41 & 903 & 0.44 \\
\hline $\begin{array}{l}\text { Yellow Cu-Sn alloy } 24.0 \mu \mathrm{m}+ \\
\text { White Cu-Sn alloy } 0.5 \mu \mathrm{m}+\text { chromium }\end{array}$ & 14 & 1490 & 0.73 \\
\hline
\end{tabular}

Comparing copper tin alloy with nickel samples, it appears that $20 \mu \mathrm{m}$ of nickel plated with chromium is more corrosion resistant than $0.5 \mu \mathrm{m}$ or even $2.0 \mu \mathrm{m}$ white $\mathrm{Cu}-\mathrm{Sn}$ alloy. The corrosion rate is equal for $0.5 \mu \mathrm{m}$ white Cu-Sn alloy and $20 \mu \mathrm{m}$ nickel, both plated with chromium and showing a corrosion rate of $0.05 \mathrm{~mm}$ and $0.03 \mathrm{~mm}$ per year, respectively. The corrosion rate results showed that while increasing the thickness of the white $\mathrm{Cu}$-Sn alloy improves corrosion resistance, additional plating with chromium does not make any difference in corrosion resistance, irrespective of the thickness of white $\mathrm{Cu}$-Sn alloy plating. This set of linear polarisation results suggest that white $\mathrm{Cu}$ Sn alloy has certain potential to be more corrosion resistant than nickel if the deposit could be plated thicker. This is due to the fact that polarisation resistance increases with thickness of the white $\mathrm{Cu}$ Sn alloy.

Yellow Cu-Sn alloy was plated to a thickness of $4 \mu \mathrm{m}, 12 \mu \mathrm{m}$ and $24 \mu \mathrm{m}$ and additionally with $0.5 \mu \mathrm{m}$ of white $\mathrm{Cu}-\mathrm{Sn}$ alloy plated on top of each variant. Compared with white Cu-Sn alloy deposits only (Table 1), yellow Cu-Sn alloy deposits showed much higher corrosion rates of $0.91,0.33$, and $0.13 \mathrm{~mm}$ per year, respectively. However, the results showed that thicker was the deposit, its corrosion resistance would be better.

The polarisation resistance values for the yellow $\mathrm{Cu}$-Sn alloy deposits are slightly higher than for those of nickel deposit, which shows that yellow Cu-Sn alloy deposits demonstrate improved corrosion resistance with increased deposit thickness. The yellow Cu-Sn alloy, plated at varying thicknesses with $0.5 \mu \mathrm{m}$ white Cu-Sn alloy and a finish of chromium deposit, have higher corrosion resistance compared to the deposits without chromium deposit (Table 1). This suggests that the chromium topcoat provided additional corrosion protection, but corrosion rates are still much higher than those of nickel with chromium finish.

Table 2 shows the electrochemical impedance spectroscopy data highlighting two constant phase elements (CPE1 and CPE2) values in Farad $\left(\Omega^{-1} \mathrm{~s}^{n}\right)$ for the electroplated deposits. Although CPE1 and CPE2 increased in values from the pre-deposit (without chromium) to post deposit (with chromium) for each panel of both nickel and white copper tin alloy, this pattern was not observed for yellow copper tin alloy at all deposit concentrations. The constant phase element (CPE1) 
represents the surface of the metallic deposit with polarisation resistance represented as $R_{2}$, while the constant phase element (CPE2) represents the surface of the oxide layer with polarisation resistance $R_{3}$. Here, the combined $R_{2}$ and $R_{3}$ would give the overall polarisation resistance $\left(R_{\mathrm{p}}\right)$. The corresponding two time constant-electrical equivalent circuit used for impedance data fitting is presented in Figure 6.

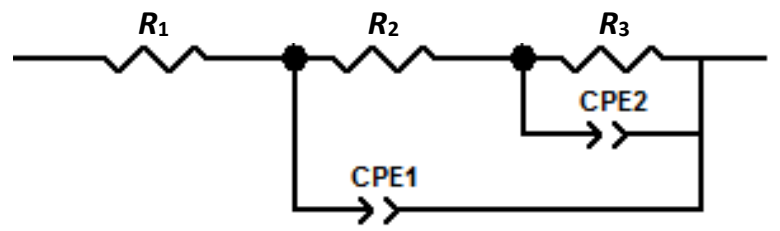

Figure 6. Two time constant-electrical equivalent circuit used to fit the EIS data

While the oxide layer response appears in the high frequency area of impedance spectrum, the low frequency section shows the response of the metallic layer with the metal/solution interface at the bottom of the pores [18]. A study by Girault et al. [18] used this equivalent circuit for the interpretation of a passivated nickel deposit and although not directly related to this study, it does confirm that chromium oxidizes to give a protective chromium oxide layer. Application of electrical equivalent circuit from Figure 6 is also supported by the study of Arslan et al. [19] with an oxide layer on a titanium substrate.

In measured electrochemical impedance spectra, two-time constants can be clearly identified in the Nyquist and Bode plots presented in Figures 7-9. Figures 7a-9a show Nyquist, while Figures $7 \mathrm{~b}-9 \mathrm{~b}$ show Bode plots of the nickel with and without chromium, the white Cu-Sn alloy with and without chromium and the yellow Cu-Sn alloy with and without chromium deposits, respectively.

Electrical equivalent circuit shown in Figure 6, however, did not always clearly fit high frequency data of impedance spectra, which could be due to a third-time constant that was not identified in this study. However, the two-time constant-electrical equivalent circuit was still the best for fitting the data collected. Here, CPE1 could be ascribed to the chromium and CPE2 to the nickel with a suspected oxide layer which was not identifiable from the data. The constant phase element CPE1 with a value of $1-7 \times 10^{-5} \mathrm{~F}$ is achieved in this study with the exception of yellow Cu-Sn alloy deposit with CPE1 value of about $2 \times 10^{-4} \mathrm{~F}$ [20]. The topography of the yellow $\mathrm{Cu}-\mathrm{Sn}$ alloys shows that the surface is rougher than the other deposits [1]. An increase in surface roughness is an indication that the overall surface area is larger than the nominated area of $1 \mathrm{~cm}^{2}$ and as a consequence, the CPE value could be higher than expected. The CPE2 value is found to be about $1 \times 10^{-4}-1 \times 10^{-3} \mathrm{~F}$, thus indicating neither metallic corrosion, nor the presence of an oxide layer.

Table 2. EIS results for all electroplated deposits

\begin{tabular}{|c|c|c|c|}
\hline Panel identification & $R_{\mathrm{p}} / \mathrm{k} \Omega \mathrm{cm}^{2}$ & $\mathrm{CPE} 1 \times 10^{5}, \mathrm{~F}$ & $\mathrm{CPE} 2 \times 10^{4}, \mathrm{~F}$ \\
\hline Nickel $20 \mu \mathrm{m}$ & 36.1 & 1.2752 & 0.6421 \\
\hline Nickel $20 \mu m+C r$ & 22.1 & 7.0763 & 1.7562 \\
\hline White $\mathrm{Cu}$-Sn alloy $0.5 \mu \mathrm{m}$ & 17.3 & 2.6074 & 1.5468 \\
\hline White Cu-Sn alloy $2.0 \mu \mathrm{m}$ & 17.3 & 3.6444 & 3.9618 \\
\hline White $\mathrm{Cu}$-Sn alloy $0.5 \mu \mathrm{m}+\mathrm{Cr}$ & 8.7 & 4.5903 & 6.8690 \\
\hline White Cu-Sn alloy $2.0 \mu \mathrm{m}+\mathrm{Cr}$ & 13.5 & 4.9812 & 6.7480 \\
\hline Yellow Cu-Sn alloy $4.0 \mu \mathrm{m}$ & 0.178 & 6.7232 & 2.0780 \\
\hline Yellow Cu-Sn alloy $12.0 \mu \mathrm{m}$ & 2.6 & 17.670 & 16.185 \\
\hline Yellow Cu-Sn alloy $24.0 \mu \mathrm{m}$ & 3.3 & 1.3094 & 1.8789 \\
\hline Yellow Cu-Sn alloy $4.0 \mu \mathrm{m}+\mathrm{Cr}$ & 8.8 & 4.1168 & 9.8390 \\
\hline Yellow Cu-Sn alloy $12.0 \mu \mathrm{m}+\mathrm{Cr}$ & 14.1 & 1.4041 & 0.4123 \\
\hline Yellow Cu-Sn alloy $24.0 \mu \mathrm{m}+\mathrm{Cr}$ & 14.0 & 1.2311 & 8.4956 \\
\hline
\end{tabular}



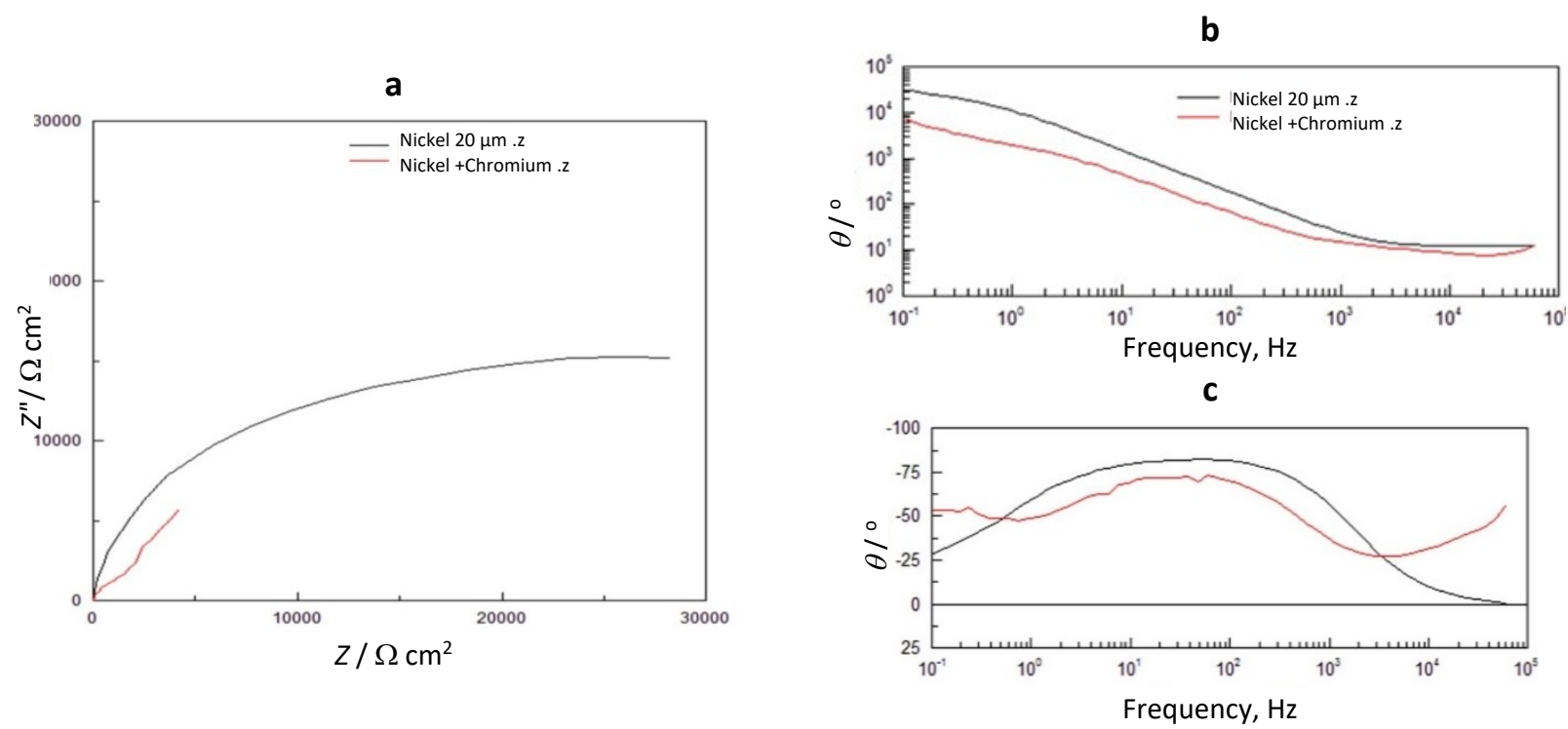

Figure 7. $\boldsymbol{a}$ - Nyquist plots for the nickel deposit with and without chromium, and Bode plots for the nickel deposit $\boldsymbol{b}$ - with and $\boldsymbol{c}$ - without chromium

a

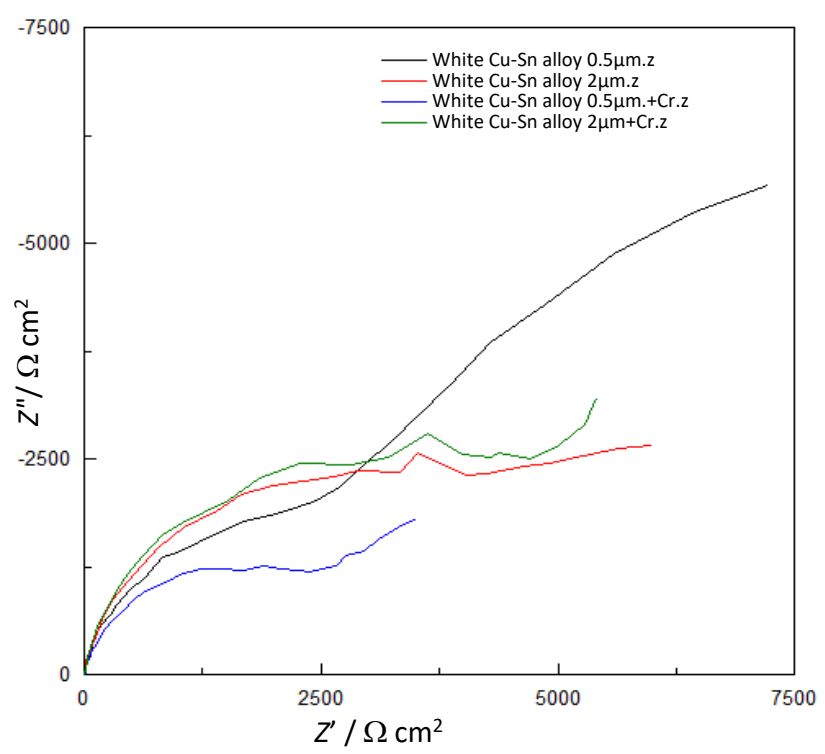

b

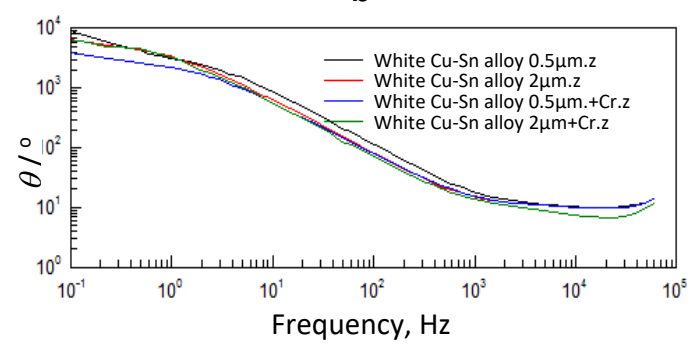

C

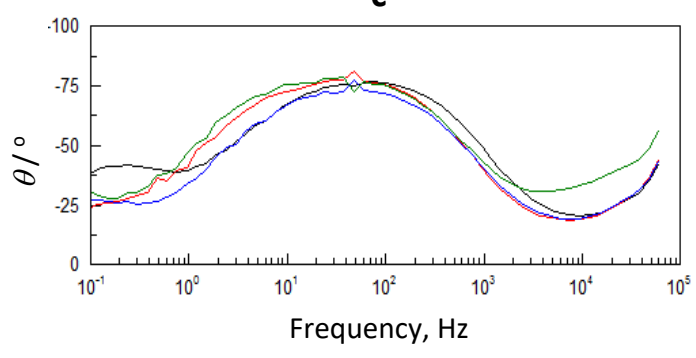

Figure 8. $\boldsymbol{a}$-Nyquist plot for the white Cu-Sn alloy deposit with and without chromium and Bode plot for the white CU-Sn alloy deposit $\boldsymbol{b}$ - with and $\boldsymbol{c}$ - without chromium

\section{Copper accelerated acetic acid salt spray (CASS) corrosion test results}

CASS corrosion testing was carried out continuously over a period of 16 hours with corrosion rating taken every 8 hours since it is an aggressive test. The test was stopped after 16 hours due to the deterioration of the nickel deposit with no chromium as a top coat.

Table 3 shows data for CASS testing of the various panels with and without chromium deposition, broken down into two chunks of 8 hours testing durations. Data is shown as $X / Y$ (already described in the Experimental section) where $X$ stands for protection rating (extent of corrosion undergone by the substrate) and $Y$ stands for appearance rating of the plating. $X$ or $Y$ is a value on a scale of 1 to 10 , where 10 is perfect (no corrosion). For instance $20 \mu \mathrm{m}$ nickel after 8 hours of CASS testing was $2 / 2$, indicating high corrosion for both substrate and plating and this got worse after 16 hours deteriorating to $1 / 1$. For $20 \mu \mathrm{m}$ nickel plus chromium plating, corrosion performance at after 8 hours of testing was excellent $10 / 10$ without any evidence of corrosion on both substrate and plating. 
After 16 hours, however, there was a minor deterioration of the plating. Comparatively, white copper tin alloy $(0.5 \mu \mathrm{m})$ was $4 / 4$ after 8 hours and $2 / 2$ after 16 hours. The corrosion performance was better than nickel. However, corrosion was worse when plated with chromium; $7 / 7$ after 8 hours and $6 / 6$ after 16 hours.

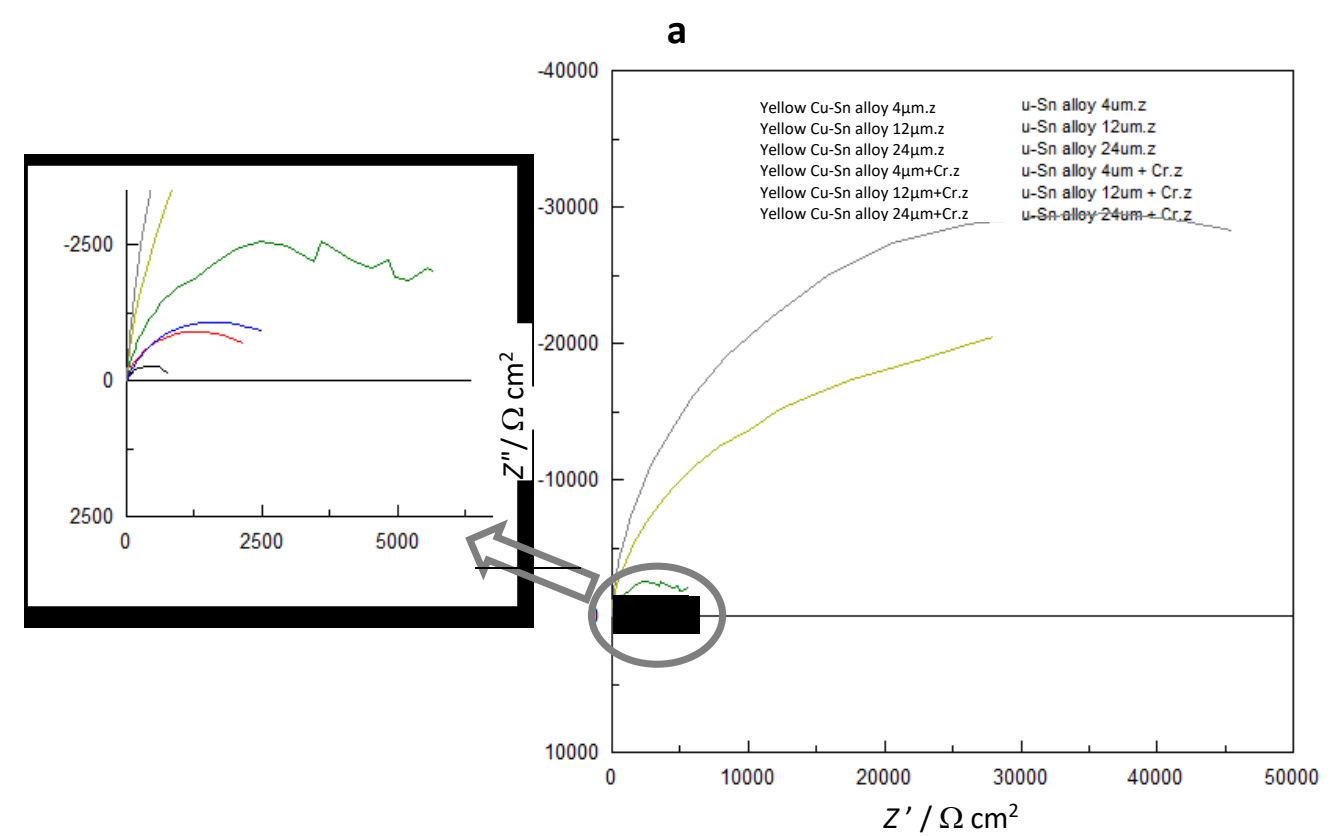

b

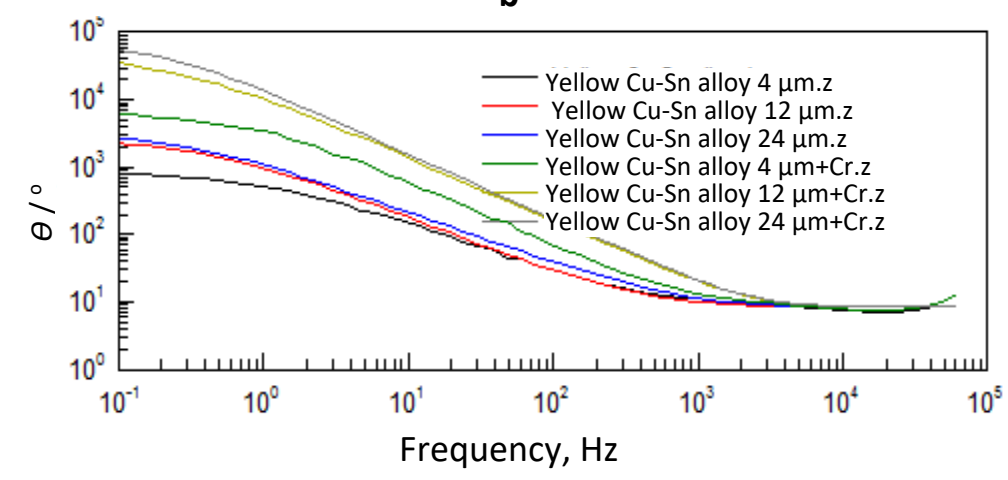

c

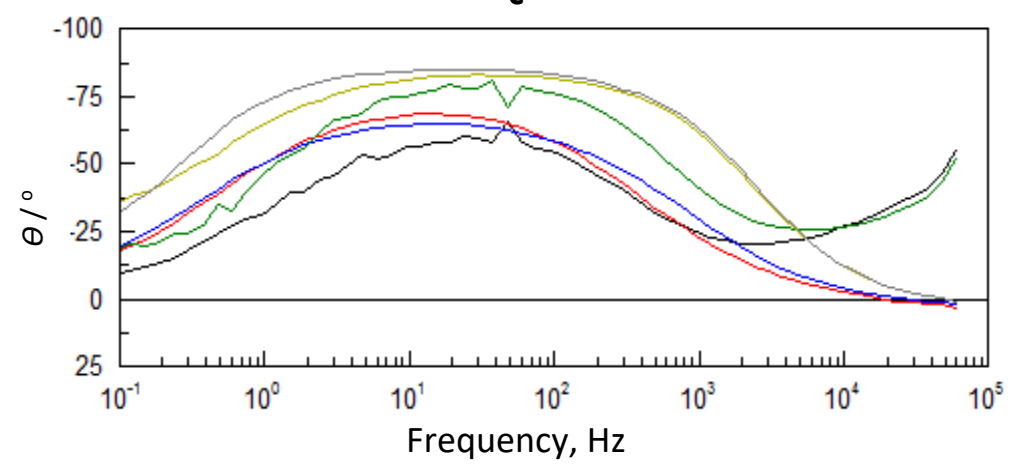

Figure 9. a-Nyquist plot for the yellow CU-Sn alloy deposit with and without chromium and Bode plots for the yellow CU-Sn alloy deposit $\boldsymbol{b}$ - with and $\boldsymbol{c}$ - without chromium

For yellow copper tin alloy plus $0.5 \mu \mathrm{m}$ white copper tin alloy, the corrosion performances were all better than for white copper tin alloy but identical when plated with chromium. Overall, corrosion performance for yellow copper tin alloy improved with coating thickness but unfortunately the surface finish deteriorated with coating thickness and therefore loss of lustre effect. 
Table 3. CASS results for all electroplated deposits

Panel identification CASS after 8 hours

\begin{tabular}{lcc}
\hline Nickel $20 \mu \mathrm{m}$ & $2 / 2$ & $1 / 1$ \\
\hline Nickel $20 \mu \mathrm{m}+\mathrm{Cr}$ & $10 / 10$ & $10 / 8$ \\
\hline White Cu-Sn alloy $0.5 \mu \mathrm{m}$ & $4 / 4$ & $2 / 2$ \\
\hline White Cu-Sn alloy $2.0 \mu \mathrm{m}$ & $4 / 4$ & $4 / 4$ \\
\hline White Cu-Sn alloy $0.5 \mu \mathrm{m}+\mathrm{Cr}$ & $7 / 7$ & $6 / 6$ \\
\hline White Cu-Sn alloy $2.0 \mu \mathrm{m}+\mathrm{Cr}$ & $6 / 6$ & $5 / 5$ \\
\hline Yellow Cu-Sn alloy $4.0 \mu \mathrm{m}+$ White Cu-Sn alloy $0.5 \mu \mathrm{m}$ & $5 / 5$ & $2 / 2$ \\
\hline Yellow Cu-Sn alloy $12.0 \mu \mathrm{m}+$ White Cu-Sn alloy $0.5 \mu \mathrm{m}$ & $3 / 3$ \\
\hline Yellow Cu-Sn alloy $24.0 \mu \mathrm{m}+$ White Cu-Sn alloy $0.5 \mu \mathrm{m}$ & $3 / 3$ \\
\hline Yellow Cu-Sn alloy $4.0 \mu \mathrm{m}+$ White Cu-Sn alloy $0.5 \mu \mathrm{m}+\mathrm{Cr}$ & $6 / 5$ \\
\hline Yellow Cu-Sn alloy $12.0 \mu \mathrm{m}+$ White Cu-Sn alloy $0.5 \mu \mathrm{m}+\mathrm{Cr}$ & $5 / 5$ \\
\hline Yellow Cu-Sn alloy $24.0 \mu \mathrm{m}+$ White Cu-Sn alloy $0.5 \mu \mathrm{m}+\mathrm{Cr}$ & $8 / 6$ & $6 / 6$
\end{tabular}

All these results suggest that chromium plays a significant role in protecting the substrate regardless of the underlying deposits but could not match the corrosion resistance of the nickel with chromium top layer. Therefore, yellow copper tin alloy (plus white copper tin alloy) is not a suitable alternative to the current nickel/chromium plating.

Overall, the CASS results summarized in Table 3 showed that none of the alternative deposits with chromium top layer could be a potential replacement for the nickel/chromium deposit although the white and yellow Cu-Sn alloy deposits were promising to be more corrosion resistant than the nickel deposit. The results suggest that while chromium helps to provide corrosion protection, the underlying deposit has a larger influence on the corrosion protection of the substrate holistically.

The white and yellow Cu-Sn alloys provide corrosion properties that have an advantage over the nickel deposit, but when used in the process of plating chromium as a top coat the corrosion properties diminish. This leaves the standard nickel with chromium plating by far the best in terms of providing corrosion protection to the substrate. If corrosion protection was not the primary objective, then $0.5 \mu \mathrm{m}$ white Cu-Sn alloy plated with chromium on top has the potential to replace nickel with chromium in terms of appearance but this would not satisfy the requirement, overall.

\section{Atomic force microscopy (AFM) data}

Atomic force microscope (AFM) was used to illustrate the surface topography of each electroplated deposit and to calculate the RMS (root mean square, average height deviations), Ra (average roughness) and $R_{\max }$ (maximum roughness between the lowest and highest points). These roughness results are for all deposits collected in Table 4.

Table 4. AFM roughness results for all electroplated deposits

\begin{tabular}{|l|c|c|c|}
\hline Panel identification & RMS, $\mathbf{n m}$ & $\boldsymbol{R}_{\mathbf{a}} / \mathbf{n m}$ & $\boldsymbol{R}_{\max } / \mathbf{n m}$ \\
\hline Nickel $20 \mu \mathrm{m}$ & 3.08 & 2.46 & 18.6 \\
\hline Nickel $20 \mu \mathrm{m}+\mathrm{Cr}$ & 3.91 & 3.1 & 36.6 \\
\hline White Cu-Sn alloy $0.5 \mu \mathrm{m}$ & 8.3 & 6.63 & 13 \\
\hline White Cu-Sn alloy $2.0 \mu \mathrm{m}$ & 12 & 9.42 & 33.7 \\
\hline White Cu-Sn alloy $0.5 \mu \mathrm{m}+\mathrm{Cr}$ & 5.61 & 4.48 & 80 \\
\hline White Cu-Sn alloy $2.0 \mu \mathrm{m}+\mathrm{Cr}$ & 9.84 & 7.84 & 276 \\
\hline Yellow Cu-Sn alloy $4.0 \mu \mathrm{m}$ & 41.2 & 33.6 & 452 \\
\hline Yellow Cu-Sn alloy $12.0 \mu \mathrm{m}$ & 71.4 & 57.9 & 408 \\
\hline Yellow Cu-Sn alloy $24.0 \mu \mathrm{m}$ & 60.8 & 49.5 & 150 \\
\hline Yellow Cu-Sn alloy $4.0 \mu \mathrm{m}+\mathrm{Cr}$ & 22.9 & 18.4 & 464 \\
\hline Yellow Cu-Sn alloy $12.0 \mu \mathrm{m}+\mathrm{Cr}$ & 66.4 & 53.1 & 639 \\
\hline Yellow Cu-Sn alloy $24.0 \mu \mathrm{m}+\mathrm{Cr}$ & 107 & 84.4 & 58.5 \\
\hline Copper $20 \mu \mathrm{m}$ & 5.92 & 4.69 & \\
\hline
\end{tabular}


Figures 10a and 10b show AFM images for the nickel deposit with and without chromium, respectively [1]. The nickel deposit appears bright and reflective, showing a relatively smooth finish. The $R_{\max }$ value of $18.6 \mathrm{~nm}$ supports this view with a small distance between the maximum and minimum points in the deposit. The RMS value of $3.08 \mathrm{~nm}$ also indicates little height deviation across the deposit. Chromium used as topcoat has the $R_{\max }$ value of $36.6 \mathrm{~nm}$ with RMS value of $3.91 \mathrm{~nm}$, the chromium is still a visually bright and reflective finish but with increased roughness in the topography in relation to the nickel deposit.

a

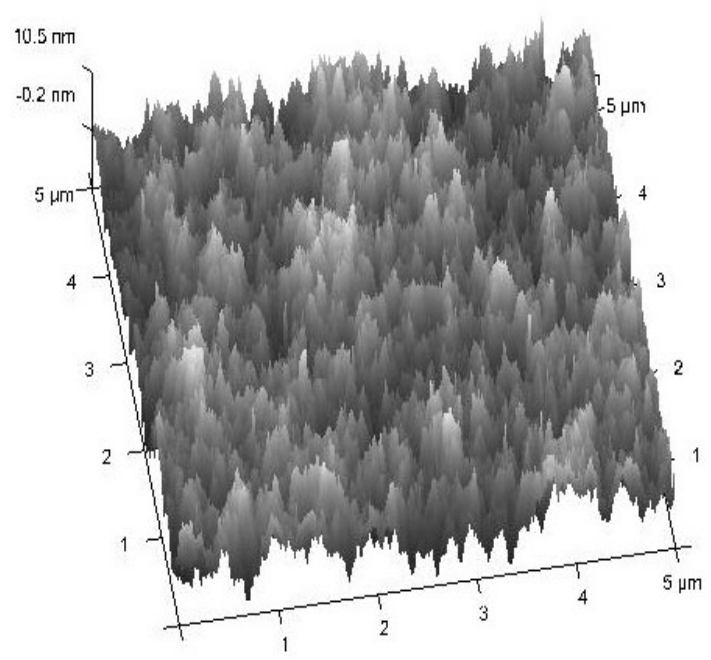

b

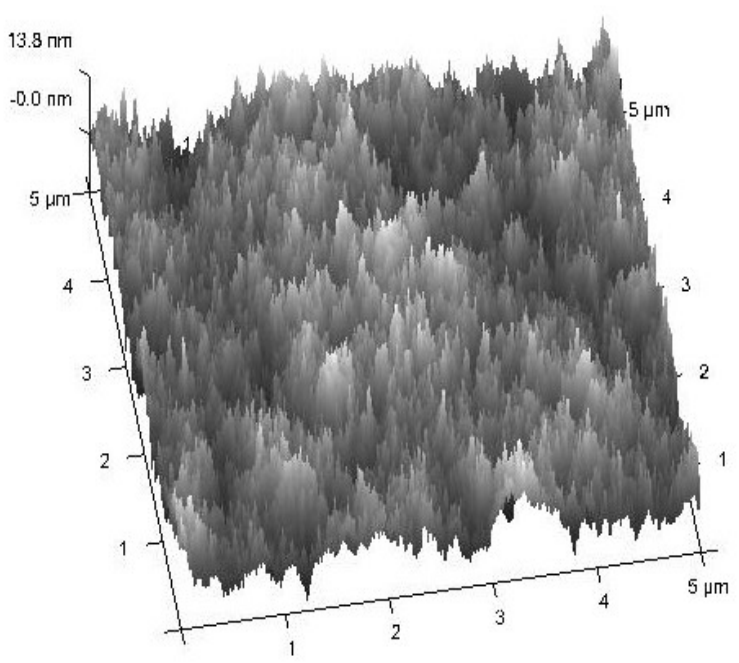

Figure 10. Atomic Force Microscopy data for deposition of $\boldsymbol{a}-20 \mu \mathrm{m}$ nickel on substrate; b - $20 \mu \mathrm{m}$ nickel and $0.3 \mu \mathrm{m}$ chromium on substrate

Figures 11a and 11b show the AFM image of the yellow Cu-Sn alloy plated to a thickness of $4.0 \mu \mathrm{m}$. The deposit is dull and has increased roughness. The $R_{\max }$ value is $276 \mathrm{~nm}$ and the RMS value is $41.2 \mathrm{~nm}$, which is considerably rougher compared to the nickel deposit. The chromium as a topcoat reduces the roughness of the deposit giving $R_{\max }$ value of $150 \mathrm{~nm}$ and RMS value of $22.9 \mathrm{~nm}$, still rougher than the standard nickel and chromium deposit.

a

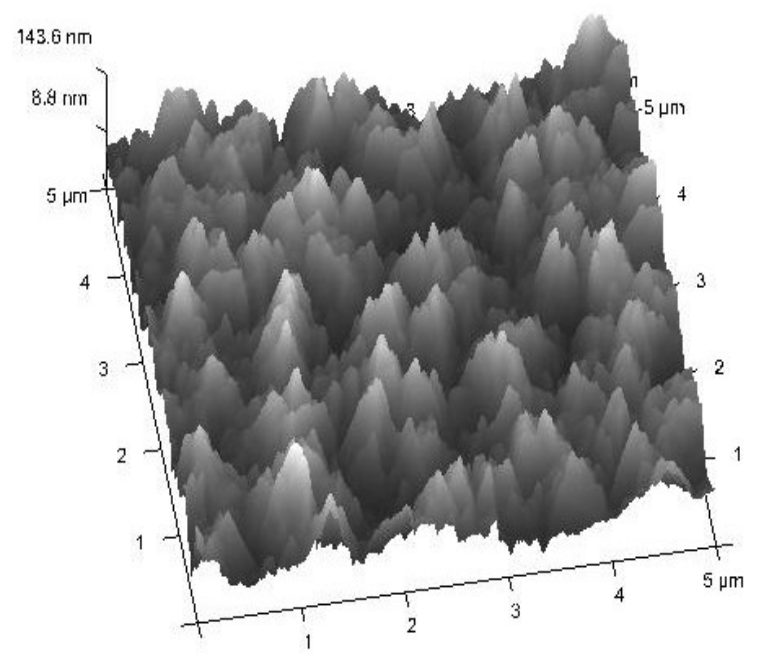

b

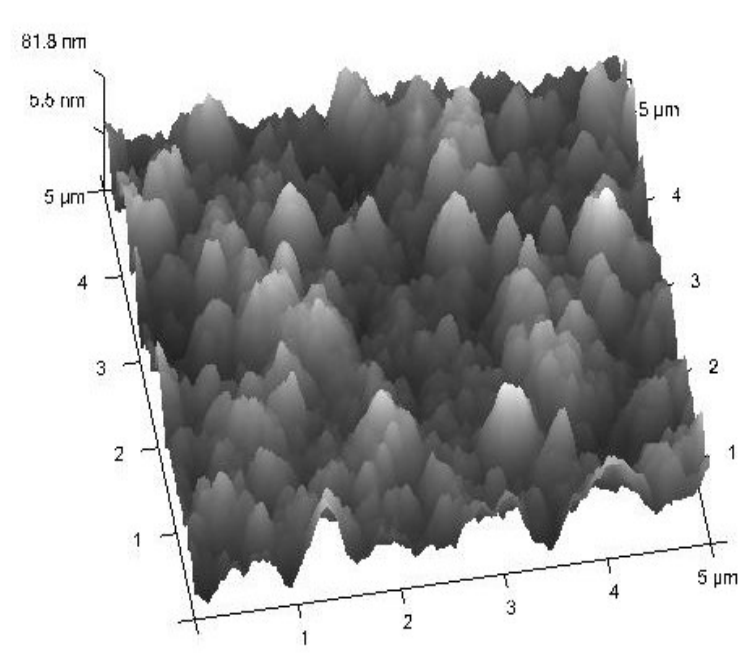

Figure 11. Atomic force microscopy data for deposition of a-4.0 $\mu \mathrm{m}$ Yellow CU-Sn on substrate; b - $4.0 \mu \mathrm{m}$ Yellow Cu-Sn and $0.3 \mu \mathrm{m}$ chromium on substrate 


\section{Conclusion}

Corrosion testing for various plated copper tin alloys, with and without plated chromium, showed that resistance to corrosion was dependent on a combination of different factors, including the thickness of chromium plating, type of material, type of testing and duration of testing in a corrosion chamber. While linear polarisation experiment was useful to establish corrosion rate of sample, electrochemical impedance and accelerated destructive testing experiments assessed corrosion resistance of the materials.

The results showed that the standard nickel with chromium top coat deposit could be replaced by $0.5 \mu \mathrm{m}$ white $\mathrm{Cu}$-Sn alloy with chromium top coat deposit for applications where appearance is of primary importance and little corrosion protection is necessary. However, for applications that require corrosion protection, no suitable alternative was found to replace nickel with chromium deposit. Consequently, for majority of applications that currently use nickel with chromium deposit for corrosion protection, there is no suitable alternative evaluated in the course of this study.

Acknowledgements: The authors wish to thank Engineering and Physical Sciences Research Council(EPSRC) for sponsorship of this Industry Case award

\section{References}

[1] S. L. Hingley, C. F. Oduoza, Journal of Materials Science and Engineering B 1 (2011) 410-420.

[2] W. S. Tait, An introduction to electrochemical corrosion testing for practicing engineers and Scientists, USA, Plan O Docs Publications, 1994.

[3] G. Rocchini, Corrosion Science 36(4) (1994) 567-581.

[4] F. Altmayer, Metal Finishing 97(1) (1999) 584-590.

[5] F. A. Lowenheim, Electroplating - Fundamentals of surface finishing. New York, McGraw-Hill Book Company, 1978.

[6] R. Singleton, Metal Finishing 110 (9) (2012) 12-19.

[7] S. L. Hingley, Characterisation of Potential Replacements for Nickel Compounds used in Decorative Chromium Plating, PhD Thesis, University of Wolverhampton, UK, 2013.

[8] V. F. Lvovich, F. Vadim, Impedance Spectroscopy - Applications to electrochemical and dielectric phenomena. New York, John Wiley and Sons, 2012.

[9] M. E. Orazem, B. Tribollet, Electrochimica Acta 53 (2008) 7360-7366.

[10] X. Xu, L. Zhu, W. Li, H. Liu, Applied Surface Science, 257 (2011) 5524-5528.

[11] R. Bostan, S. Varvara, L. Gaina, L. Muresan, Corrosion Science 63 (2012) 275-286.

[12] H. Jafari, M. H. Idris, A. Ourdjini, H. Rahimi, B. Ghobadian, Fuel 90 (2011) 1181-1187.

[13] Gramry-Instruments, Basics of electrochemical impedance spectroscopy, http://www.gamry.com/assets/Application-Notes/Basics-of-EIS.pdf (December, 2017).

[14] ASTM "ASTM B537-70." www.astm.org/Standards/B537.htm (December, 2017).

[15] ASTM "ASTM B117-07." http://www.astm.org/Standards/B117.htm (December, 2017).

[16] M. Kouril, P. Novak, M. Bojko, Cement \& Concrete Composites, 28 (2006) 220- 225.

[17] R. C. Weast, M. J. Astle, CRC Handbook of Chemistry and Physics, Florida, CRC Press Inc., 1980.

[18] H. Girault, Journal of Electroanalytical Chemistry 504 (2001) 96-103.

[19] H. Arslan, H. Celikkan, N. Ornek, O. Ozan, A. Ersoy, M. Aksu, Journal of Applied Electrochemistry 38 (2008) 853-859.

[20] E. Radlein, G. H. Frischat, Journal of Non-Crystalline Solids 222 (1997) 69-82.

(C)2018 by the authors; licensee IAPC, Zagreb, Croatia. This article is an open-access article distributed under the terms and conditions of the Creative Commons Attribution license (http://creativecommons.org/licenses/by/4.0/) 